\title{
¿QUIÉN ES EL VERDADERO PROTAGONISTA DE LA PRUEBA DE OFICIO? ¿EL JUEZ O LAS PARTES?
}

\author{
WHO IS THE REAL PROTAGONIST OF THE PROOF OF TRADE? \\ THE JUDGE OR THE PARTIES? \\ Shirley Muñico Patillaz*, José Paz Cano*, Queni Rebatta Chirre* \\ Universidad Continental
}

Recepción: 09/10/2017

Aceptación: 20/11/2017

\section{Resumen}

Con ocasión de la presentación del Proyecto de Reforma del Código Procesal Civil peruano, los autores se enrumban en la aventura de la investigación jurídica, viendo necesario el análisis del artículo 194 del Código Procesal Civil, que refiere a la prueba de oficio, proponen un lazo tridimensional entre prueba, proceso y verdad, para luego analizar si la prueba de oficio debe ser un poder deber o un poder discrecional, de manera que advierten algunos problemas en la Reforma, inclusive se observa la puesta en peligro de la esencia de la iniciativa probatoria del juez, y es que ¿Quién es el protagonista de la prueba de oficio? ¿El juez o las partes? este trabajo también nos permitirá conocer más sobre la evolución de esta figura jurídica, asimismo la legislación comparada nos ayudará a tener mayor perspectiva; ¿recuerdan los problemas antes señalados?, pues los autores luego de ese análisis proponen algunas alternativas a manera de requisitos, principalmente se enfocan en mantener la característica primordial de la prueba de oficio y de la predictibilidad jurídica.

Palabras clave: Prueba; prueba de oficio; verdad; proceso; poder discrecional; predictibilidad y fijación de puntos controvertidos.

\begin{abstract}
As part of the presentation of the reform project of the peruvian Civil Procedural Code, the authors are in the crossing of the legal investigation, considering necessary the analysis of the article 194 of the Civil Procedural Code, which refers to the proof of trade, propose a three-dimensional bond between proofs, process and truth, and then analyze whether the proof of trade should be a duty power or discretionary power, identifying some problems in the reform, including Observed Endangering the essence of the judge's probation initiative, and who is the protagonist of the proof of trade? The judge or the parties? This work will also allow us to know more about the evolution of this legal figure, also the compared legislation will help us to have a greater perspective; Do you remember the problems? after that, the authors analysis propose some alternatives as requirements, mainly focus on maintaining the primary characteristic of the proof of trade and legal predictability.
\end{abstract}

Keywords: Proof; proof of trade; truth; process; discretionary power; predictability and fixation of controversial points.

* $\quad$ Estudiantes de Derecho en la Universidad Continental. Integrantes del Grupo de Investigación Proceso \& Argumentación. 


\section{INTRODUCCIÓN}

Recordemos. Hace décadas el juez carecía de poder para disponer oficiosamente la práctica de pruebas, pues, en aquel sistema tradicional se evidenciaba al «juez convidado de piedra», es decir, el proceso dependía únicamente de lo ofrecido por las partes, por tanto, el juez tenía un rol pasivo y se limitaba a decidir en base a lo presentado, sin importar que dichas pruebas se mostrasen insuficientes.

Se sabe que las pruebas son instrumentos que, a través de la historia judicial, han permitido probar hechos controvertidos para que el juez fundamente sus decisiones. ¿Cuán importante es entonces contar con pruebas suficientes?

Es la ciencia procesal alemana del siglo XIX la que sustenta que la disposición del derecho material le corresponde - efectivamente- a las partes; no obstante, ello no significa que dispongan del proceso, superando así el sistema procesal privatístico, dando paso al sistema procesal publicístico.

Ahora el rol del juez es activo, él es director del proceso, tiene el poder en la actividad probatoria. Sin embargo, esta comparación entre sistemas procesales resulta para algunos desfasada. Por ello, Mirjan Damaška ha planteado otros dos modelos procesales, el primero tiene como finalidad del proceso la resolución de conflictos y el segundo está dirigido a la implementación de políticas públicas mediante la aplicación del derecho previamente establecido por el legislador. Respecto al primero, se puede decir que apunta a un ideal de justicia procedimental, siendo el juez necesariamente pasivo, las partes gobiernan el proceso y su función es delimitada especialmente en la práctica probatoria.

En nuestro actual Código Procesal Civil, la finalidad del proceso es resolver conflictos, quizá con un criterio en el que el director del proceso es el juez, pero con un fin ideal (subjetivo), mientras que el proyecto de reforma del Código Procesal Civil en el artículo III de su Título Preliminar plantea que la finalidad del proceso es brindar una adecuada, oportuna y eficaz protección a los derechos e intereses, subsumiéndose en el criterio de las políticas públicas. Sin lugar a duda, este planteamiento es muy acertado porque al juez le tiene que importar que el proceso lo gane quien deba ganarlo, de acuerdo con la regulación y los hechos, todo ello con base a la verdad probada.

La regulación de la prueba de oficio en la legislación peruana ha ido cambiando, pues en el recuento legal del artículo 194 tenemos la versión ori- 
ginal en el Código Procesal Civil de 1993, que luego fue modificado por el Proyecto de Ley N. ${ }^{\circ}$ 1326/2011 y finalmente su última versión en la Ley N. ${ }^{\circ}$ 30293. Sumado a ello, el Proyecto de Reforma del Código Procesal Civil. Es necesario mencionar que el Derecho sufre estos cambios debido a su objeto de estudio.

La sociedad, cada día, debido a la libertad y el respeto a sus derechos, logra adquirir su máxima libertad y así gana derechos relacionados a su correcto e ideal desarrollo como persona, trayendo esto como consecuencia la reafirmación de la dignidad humana, esto último, como la finalidad y el fin supremo de nuestro Estado peruano. Claro ejemplo de lo mencionado, son los eventos sociales que sucedieron alrededor del mundo este último año. En Argentina, en cuanto a la despenalización del aborto, las personas realizaron grandes movimientos para reclamar este «derecho»; fue tanta la presión que se generó que este pedido fue debatido en su respectivo órgano legislador. Por otro lado, en la India sucedió un hecho histórico, después de 150 años, se despenalizó la homosexualidad; sin duda, un derecho que encuentra su base en el derecho de la libertad, específicamente el de la libertad sexual. Con estos dos ejemplos se acredita el constante cambio de la sociedad, es así cómo se generan diferentes relaciones materiales y. a su vez, los conflictos que se generan a causa de estas relaciones son novedosos y, como tienen esta característica, las herramientas que el derecho procesal desarrolla en su doctrina y en su derecho adjetivo probablemente no sean tan eficaces para la resolución de dichos conflictos, por lo que tienen que brindarse nuevos mecanismos o actualizar los ya regulados para su correcta eficacia.

Debido al Proyecto de Reforma del Código Procesal Civil, nos parece interesante observar y analizar los aspectos y novedades que este proyecto nos trae. Observamos que la prueba de oficio es una figura excepcional, es decir, no siempre se aplicará, siendo uno de sus requisitos indispensables la insuficiencia probatoria para demostrar la veracidad de las alegaciones de hecho y no para convencer al juez. Este primer punto es importante ya que el convencimiento es subjetivo, se basa en la psicología.

No cabe duda alguna que la iniciativa probatoria del juez debe aplicar tanto para la primera como para la segunda instancia. Lo importante radica en determinar si debe ser un poder deber o un poder discrecional. La Ley N. 30293 la regula como un mandato (ordenará) y el proyecto de reforma como una facultad (puede). Debe quedar claro que al ordenarle 
al juez que actúe medios probatorios adicionales y pertinentes, podríamos generar una vasta arbitrariedad, así como gasto, tiempo y esfuerzo innecesario en el proceso. Por ello, nos parece prudente que se le otorgue el poder discrecional al juez.

Ahora bien, respecto a que el juez debe informar previamente a las partes la necesidad de incorporar un medio probatorio sobre algún hecho que a su juicio no estaría probado, las partes deben ofrecer el medio probatorio necesario solicitado por el juez en un plazo de 6 días. Claro está, que es necesaria la comunicación previa para la actuación de la iniciativa probatoria del juez; sin embargo, al proponer que las partes ofrezcan medios probatorios, ¿esto no se configuraría en una prueba extemporánea? ¿Amerita o no que esté regulado en el artículo 194? Entonces, ¿Quién es el protagonista de la prueba de oficio? ¿El juez o las partes?

Es pertinente que se le otorgue a la otra parte un plazo para que pueda ejercer su derecho a la defensa, también puede ofrecer más pruebas, y es que 6 días - otra vez- resultan insuficientes. Estamos equiparando ello para todos los procesos como el de conocimiento, el abreviado y otros, sin tomar en cuenta la complejidad del proceso, la actitud del demandado y del demandante.

En las siguientes líneas iremos aclarando el panorama e intentaremos plantear algunas propuestas; para ello, partiremos de la aproximación a la prueba de oficio y su evolución, además determinaremos el lazo entre prueba, proceso y verdad, para luego analizar si esta figura jurídica vulnera principios o garantías de manera que quede claro si la prueba de oficio es un poder deber o un poder discrecional. Avizorando algunos problemas que trae consigo la Reforma, en tanto se plantean propuestas y requisitos.

\section{APROXIMACIÓN A LA PRUEBA DE OFICIO Y SU EVOLUCIÓN}

\subsection{El lazo entre prueba, proceso y verdad}

Para aproximarnos al concepto de prueba de oficio y su importancia, es importante que analicemos y tengamos claro que existe una conexión de la prueba y verdad con el proceso; como refería Taruffo (2013), «la averiguación de la verdad de los hechos es condición necesaria para la justicia de la decisión, ya que ninguna decisión puede considerarse justa si se basa 
en una averiguación falsa o errónea de los hechos relevantes» (pp. 13-24). No podemos ser enemigos de la verdad, mucho menos en un Estado Constitucional de Derecho; si bien es cierto, no siempre se llega a la verdad absoluta, sí podemos hablar de una verdad probada, de manera que el juez fundamente la decisión en una reconstrucción de los hechos relevantes, obviamente, con base en la evaluación racional de las pruebas.

Ser verdadero y ser tenido por verdadero es el punto de partida para - probablemente - resolver la tan tediosa relación entre prueba y verdad. Jordi Ferrer (2005, p. 84) refiere «que la finalidad de la prueba como institución jurídica es la de permitir alcanzar el conocimiento acerca de la verdad de los enunciados fácticos del caso, cuando los elementos u medios específicos de prueba logran acreditar la verdad de una proposición, se puede considerar entonces que está probada y en ese caso, el juez deberá incorporar dicha proposición y sus elementos a su razonamiento decisorio y tenerla por verdadera».

Ciertamente, la relación tridimensional entre la prueba, verdad y proceso es un lazo que no debe quebrarse. Cuando el juez, en ejercicio de sus funciones, vaya a tomar la decisión del caso, debe haber valorado las pruebas pertinentes para brindar una adecuada, oportuna y eficaz protección a los derechos e intereses individuales y de titularidad colectiva y difusa, ante cualquier lesión o amenaza en la que se encuentren. No obstante, en el camino del proceso se presentarán dificultades. Por ejemplo, cuando el juez se encuentre frente a pruebas insuficientes, él debe continuar con este lazo, debe incorporar pruebas que le permitan tomar una decisión, aparece así la prueba de oficio. A continuación, representaremos gráficamente lo dicho:

Gráfico 1. Prueba de oficio.
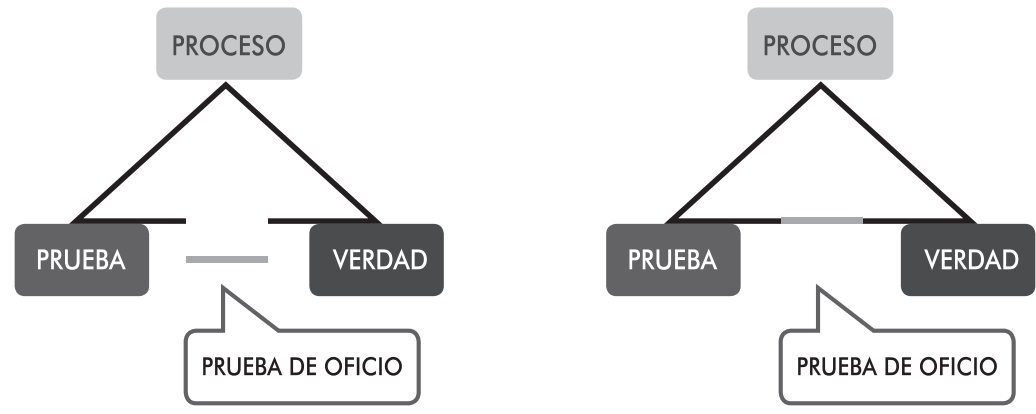

Fuente: Elaboración propia. 
Notemos que debe existir una armonía entre la prueba y la verdad en el proceso. Sin embargo, este lazo puede romperse por insuficiencia probatoria, actuando como especie de parche acudimos a la prueba de oficio, de manera que nos aproximemos a la verdad a través de la comprobación de los hechos controvertidos.

No debemos olvidar que este esquema dilucida mejor la idea de que la verdad es la relación entre el enunciado y la realidad, mientras que la verdad del enunciado es la relación de éste con los hechos suscitados, entonces son las pruebas las que justifican la decisión final, y con ellas sabremos si realmente existen o no buenas razones para aceptar el acercamiento a la verdad, hablando así de una verdad respecto del modelo ideal de la perfecta correspondencia.

La verdad absoluta queda desterrada, porque así como no se puede llegar a ésta, tampoco los medios probatorios nos llevan a ello. Recordemos el mito de Sísifo, quien tenía que empujar perpetuamente un peñasco gigante montaña arriba hasta la cima, ahora imaginemos que el juez es Sísifo y que esa cima es la verdad. El peñasco es el cúmulo de pruebas. Lo que tratamos de decir es que si bien resulta muy complicado acceder siempre a la verdad, durante el proceso siempre se debe aspirar a ella.

\subsection{Prueba insuficiente}

Si bien es cierto, la palabra insuficiente denota una escasez o cortedad de algo (RAE, http://www.rae.es/); sin embargo, en un proceso, ¿este término debe ser tomado de una forma objetiva? $\mathrm{O}$ tal vez, ¿quién es el que percibe esta insuficiencia? En este proceso existen elementos que cumplen una función relevante, una de ellas es el tema de prueba, y si es posible afirmar que es la etapa en donde se marca el rumbo de la sentencia, ¿qué pasa si el juez no logra avizorar la probanza de hechos controvertidos? ¿Qué decisión dará el juez si tiene esa pieza faltante para que pueda dictar una sentencia que le parezca correcta ligada a la verdad probada? Es en este momento en el que el juez se da cuenta de que le falta algo, una insuficiencia, para tomar su decisión. Este es el primer peldaño a las preguntas realizadas al principio, hablar de una prueba insuficiente nos lleva directamente al plano subjetivo, un lugar que dependerá de cada individuo y en este caso, aquel que percibe esa insuficiencia es el juez. En otras palabras, afirmamos que el único individuo capaz de sentir esta insuficiencia dentro de la prueba 
es el juez. Estamos de acuerdo en que los medios probatorios son el vehículo mediante el cual el juez obtiene la prueba respecto de las posiciones asumidas por las partes en un proceso judicial. La etapa y actividad probatoria es muy relevante para la correcta administración de justicia y para el proceso, tanto así que Jeremías Bentham (citado por Arazi, 1995) decía que «el arte del proceso no es otra cosa que el arte de saber administrar el material probatorio, la actividad probatoria debe ser de la más alta calidad y cantidad».

En estas líneas aprovecharemos para hacer una breve comparación: en el artículo 188 del Código Procesal Civil se prescribe que "[l]os medios probatorios tienen por finalidad acreditar los hechos expuestos por las partes, producir certeza en el juez respecto de los puntos controvertidos y fundamentar sus decisiones»; mientras que el Proyecto de Reforma menciona que «[l] as partes tienen el derecho de emplear todos los medios probatorios, aunque no estén previstos expresamente en este código, a fin de probar las alegaciones de hecho que fundan sus pretensiones o defensas. El juez deberá respetar los derechos al ofrecimiento, admisión, actuación y valoración de los medios probatorios, justificando racionalmente su decisión sobre los hechos». De estas disposiciones, un gran cambio se presenta justamente cuando el fin del proceso ya no es producir certeza en el juez, sino probar las alegaciones de hecho, efectivamente una convicción es una creencia de que algo es o será verdadero. Entonces, ¿el Derecho es creencia? La respuesta es negativa, porque se puede estar convencido de que algún día la corrupción en el Perú acabará; sin embargo, esto no quiere decir que sea falso o futuramente verdadero, lo que pasa es que puede darse o no, y ello dependerá del cambio de algunos agentes, tal vez de la implementación de políticas públicas más estrictas, y que con cada granito de arena ayudemos a disminuirla. Pero también podría vociferar que no seré corrupto, cuando en realidad por más mínimo que sea el acto me hace corrupto. La investigación también me podría ayudar a tomar otros rumbos, y nadie sabe lo de nadie y en tanto solo creo que puede o no ser. $Y$ es que una decisión judicial no debe versar en base a creencias, solo en base a la declaración que una parte realice y solo porque esta se muestre nervioso no lo hace responsable, es sumamente subjetivo. Por el contrario, resolver en base a hechos probados convierte la decisión judicial en una correcta aplicación de derecho. 


\subsection{Aproximación al concepto, ¿prueba de oficio como poder deber o poder discrecional?}

Si consideramos que el nexo entre prueba, verdad y proceso no debe descomponerse, habremos entendido la importancia de la iniciativa probatoria del juez, conocida como prueba de oficio.

Respecto a la prueba de oficio, el profesor Devis Echandía (1985) ha señalado «que el Juez, en tanto sujeto principal de la relación jurídica procesal y del proceso, le corresponde decretar oficiosamente toda clase de pruebas que estime convenientes para el esclarecimiento de los hechos que interesen al proceso». Por su parte, Parra Quijano (2007) menciona que «el uso de esta facultad del juez es pertinente para llevar a cabo un buen análisis del acervo probatorio que lleve a la verdad del proceso», pues se están aprovechando capacidades del juez, que ahondan tanto su experiencia como su conocimiento.

Notemos que la prueba de oficio es considerada por la gran mayoría de los doctrinarios como una facultad, es decir, hablamos de un poder discrecional que se le otorga al juez para que este actúe nuevos medios probatorios, rescatamos ello, determinando que la iniciativa probatoria del juez es un poder discrecional. No podríamos hablar de la prueba de oficio como poder deber, ya que, tendríamos necesariamente que especificar parámetros particulares para su aplicación, y ello depende mucho del caso en concreto, lo que sí pretendemos — más adelante — es plantear requisitos que ayuden y salvaguarden la esencia misma de la prueba de oficio.

El altruismo limitado del ser humano es uno de los pilares generadores de los conflictos desde tiempos remotos, acrecentándose más y más cuando el poder es otorgado a un grupo de personas o a una sola, produciendo disparidades en los diferentes actos de la interacción humana, e incluso abusando del poder para con el ambiente, en general produciendo perjuicios a la colectividad. Ante ello, el rol del Estado debe ser imprescindible, más aún en el ámbito jurisdiccional donde el egoísmo yace en su máximo esplendor y, por ende, los fines estatales, como el bienestar común, quedan relegados en segundo plano; las disquisiciones sobre el protagonismo que debían jugar las partes o el juez en el proceso judicial como tema de debate ha quedado en el pasado, por ende tanto intereses privados y públicos deben transar y maximizar su desarrollo. El juez como representante del 
Estado en el ámbito de la jurisdicción debe estar respaldado por facultades que el mismo cuerpo normativo le otorgue con el respeto de las garantías mínimas constitucionales para lograr ecualizar los intereses públicos, siendo así la prueba de oficio una de estas facultades que este tercero imparcial e independiente tiene para heterocomponer la causa que es sometida a su jurisdicción. Valga mencionar que hay un margen de discrecionalidad latente en el ejercicio de esta facultad en específico, tanto en el texto procesal correspondiente como en el proyecto de reforma.

La prueba de oficio más que un poder es una responsabilidad jurisdiccional para con los justiciables, en consecuencia, es innegable la dinámica constante del sistema jurídico que debe ser maleable a los fenómenos sociales, estableciendo hitos en cuanto a decisiones ya esgrimidas con anterioridad para no recaer en decisiones contradictorias que fatalmente generan desconfianza en la ciudadanía y a la vez el dezmero de la justicia que imparte el órgano jurisdiccional, es por ello vital que todo acto discrecional encuentre un parangón en los principios constitucionales y las limitaciones que el mismo texto normativo brinda, expurgando todo aspecto decisorio plasmado en una resolución judicial donde por obvias razones prima el subjetivismo en su máximo esplendor.

El aspecto fáctico nutre al Derecho como relación inseparable entre hechotexto normativo bajo el adagio ex facto oritur ius, no se puede negar que es un paso trascendente de cambio de paradigma, de un rol pasivo a un juez más interesado en el proceso, tratando de emitir una decisión acorde a los criterios de proporcionalidad y razonabilidad, divorciándose así de la arbitrariedad, manifestando el cambio de paradigmas dogmáticos de culto de la ley a la constitucionalizarían del proceso.

\subsection{Evolución de la prueba de oficio}

\subsubsection{Sistema dispositivo y sistema inquisitivo-sistema procesal privatístico y publicístico}

Como bien indica Marianella Ledesma (2017) «en el tradicional sistema procesal privatístico se justificaba la figura del "juez convidado de piedra", pues le estaba prohibido practicar pruebas de oficio, ya que era labor privada de las partes por tanto el juez decidía respecto de lo presentado, podía contar con una buena o mala información, pero igual tomaba una decisión». Este sistema dispositivo debe percibirse en un sentido material 
cuando los hechos les pertenecen a las partes, y en sentido procesal cuando la conducción del proceso está en las partes.

Es la ciencia procesal alemana del siglo XIX la que sostiene que la libre disposición del derecho material le corresponde a las partes, pero ello no implica que estas puedan disponer del proceso para luego dar paso al sistema procesal publicístico donde el juez no se limita a juzgar sino que se convierte en un verdadero gestor del proceso, teniendo poderes como la iniciativa probatoria, este sistema inquisitivo visto en sentido material el proceso puede iniciarse de oficio e inclusive el juez puede traer nuevas pruebas buscando esclarecer aquello que es insuficiente; y en un sentido procesal la conducción del proceso está a cargo del juez.

Nuestro Código Procesal Civil reconoce el principio dispositivo en sentido material y el principio inquisitivo en sentido procesal, significa que nos encontramos en un sistema procesal mixto. Michelle Taruffo (2009) refiere que

es oportuno hablar de modelos mixtos para indicar aquellos ordenamientos procesales — que actualmente son numerosos_ en los cuales se prevé más o menos extensos los poderes de instrucción del juez, en cuanto a la plena posibilidad que las partes tienen de aportar todas las pruebas admisibles y relevantes para la certeza de los hechos.

En el Perú —en un primer momento-, se presencia el sistema inquisitivo porque la conducción del proceso está a cargo del juez, es el señor y director del proceso. En otro momento notamos que el sistema dispositivo está presente porque los hechos le corresponden a las partes, pero no significa que el juez no pueda ejercer su poder discrecional de iniciativa probatoria, nuevamente aparece el sistema inquisitivo.

\subsection{Legislación comparada}

Es pertinente tener un acercamiento a otros sistemas jurídicos en el proceso. Algunos países como Francia, Italia, Estados Unidos, España, y otros, acogen la prueba de oficio y lo incluyen dentro de las facultades del juez, con el fin de llegar a una decisión basada en percepciones y conocimientos verídicos de los hechos, de tal forma que le sea más fácil dirigir el proceso. La lista que se presentará fue obtenida de la investigación de Loly Gaitán (2010):

Francia: "Artículo 10. El Juez tiene la autoridad de ordenar de oficio todos los medios de instrucción legalmente admisibles.» [Énfasis agregado]. 
Estados Unidos: «Regla 614. Llamado e Interrogación de testigos por la Corte (a) Llamada por la corte. La corte puede, según su propia consideración o a petición de parte, llamar testigos, y todas las partes pueden interrogar los testigos llamados. (b) Interrogación por la corte. La corte puede interrogar a testigos, así sea llamado por la misma corte o por una de las partes. Regla 706. Expertos señalados por la corte (a) Cita. La corte puede según lo disponga por si misma o por las partes incorporar una orden para demostrar causa porqué los testigos expertos no deben ser designados, y pueden solicitar las partes el envío de nombramientos. La corte puede designar cualquier testigo experto acordado por las partes, y puede designar los testigos expertos de su propia selección. La corte no designará a un testigo experto a menos que el testigo consienta su actuar. [...]» [Énfasis agregado].

México: «Artículo 278. Para conocer la verdad sobre los puntos controvertidos puede el juzgador valerse de cualquier persona, sea parte o tercero, y de cualquier cosa o documento, ya sea que pertenezca a las partes o a un tercero, sin más limitación que la de que las pruebas no estén prohibidas por la ley ni sean contrarias a la moral.» «Artículo 279. Los tribunales podrán decretar en todo tiempo, sea cual fuere la naturaleza del negocio, la práctica o ampliación de cualquier diligencia probatoria, siempre que sea conducente para el conocimiento de la verdad sobre los puntos cuestionados. En la práctica de estas diligencias, el juez obrará como estime procedente para obtener el mejor resultado de ellas, sin lesionar el derecho de las partes oyéndolas y procurando en toda su igualdad.» [Énfasis agregado].

Italia: "Artículo 117. Interrogatorio no formal de las partes. En cualquier estado y grado del proceso tendrá el juzgador la facultad de ordenar la comparecencia personal de las partes en contradictorio entre sí, para interrogarlas libremente sobre los hechos del pleito. Las partes podrán hacerse asistir por los defensores.» [Énfasis agregado].

«Artículo 118. Orden de inspección de personas y de cosas. El juzgador podrá ordenar a las partes y a los terceros, que consientan sobre su persona o sobre las cosas que posean las inspecciones que aparezcan indispensables para conocer los hechos del pleito, siempre que ello pueda realizarse sin grave daño para la parte o para el tercero, y sin constreñirles a violar ninguno de los secretos previstos en los 
artículos 351 y 352 del Código de Procedimiento Penal.» «Si la parte se niega a cumplir tal orden sin justo motivo, el juzgador podrá inferir de esa negativa argumentos de prueba, conforme al apartado segundo del artículo $116 »$. «Si se niega el tercero, el juzgador lo condenará a una pena pecuniaria que no exceda de dos mil liras.»

«Artículo 439. Poderes instructorios del juez. El juez puede disponer de oficio todos los medios de prueba que considere oportunos. Puede disponer la prueba testifical aun fuera de los límites establecidos por el Código Civil.» [Énfasis agregado].

El texto resaltado en negrillas da cuenta de que en estos países vecinos la iniciativa probatoria es una facultad; nuestra legislación ha sufrido algunos cambios: un puede por un ordenará. A continuación, desarrollaremos estos cambios en nuestro Código Procesal Civil.

\subsection{La iniciativa probatoria y su evolución en la legis- lación peruana}

Para realizar un breve análisis sobre estos cambios, compartimos el Cuadro 1, elaborado por Luis Alfaro (2017), en el cual se observa el texto de las version originales del Código Procesal Civil, Proyecto de Ley N. ${ }^{\circ}$ 1326/2011-PE y la Ley N. ${ }^{\circ} 30293$; todas estas legislaciones relacionadas al artículo 194 del Código Procesal Civil.

$\mathrm{Al}$ respecto, cabe resaltar la reforma del artículo 194 de Código Procesal Civil que se produjo con la Ley N. ${ }^{\circ} 30293$ en el año 2014, ya que el anterior texto señalaba expresamente que el juez podía ordenar la actuación de los medios probatorios que considerase conveniente siempre que los ofrecidos por las partes fueran insuficientes; sin embargo, el nuevo texto ha reformado este término y ya no indica que el juez puede, sino que ahora lo ordenará, ello ya ha sido detallado en capítulos anteriores por tanto reafirmamos que es conveniente que la prueba de oficio sea un poder discrecional.

\section{2. ¿QUÉ VULNERA LA PRUEBA DE OFICIO?}

Básicamente, hablar de pruebas de oficio genera un debate entre dos proposiciones principales, aquellas que mencionan que estas pruebas de oficio no están relacionadas con la imparcialidad del juez y otra parte que menciona que tampoco se cumple una igualdad en las partes. 
Cuadro 1. Comparativo del artículo 194 del Código Procesal Civil. Recuento legal de la nueva versión del Art. 194

\begin{tabular}{|c|c|c|}
\hline $\begin{array}{l}\text { Versión original del } \\
\text { Código Procesal Civil }\end{array}$ & $\begin{array}{l}\text { Proyecto de Ley } \\
\text { N. }{ }^{\circ} 1326 / 2011-\mathrm{PE} \text {, } \\
\text { Dictamen - Comisión } \\
\text { de Justicia [primer } \\
\text { texto sustitutorio] }\end{array}$ & $\begin{array}{l}\text { Dictamen-Comisión de Jus- } \\
\text { ticia [segundo texto sustitu- } \\
\text { torio] } \\
\text { Texto aprobado [autógrafa] } \\
\text { texto promulgado } \\
\text { [Ley N. }{ }^{\circ} 30293 \text { ] }\end{array}$ \\
\hline $\begin{array}{l}\text { Art. 194. Pruebas de oficio } \\
\text { Cuando los medios } \\
\text { probatorios ofrecidos por } \\
\text { las partes sean insuficientes } \\
\text { para formar convicción, el } \\
\text { juez, en decisión motivada } \\
\text { e inimpugnable, puede } \\
\text { ordenar la actuación de } \\
\text { los medios probatorios } \\
\text { adicionales que considere } \\
\text { convenientes. } \\
\text { Excepcionalmente, el } \\
\text { juez puede ordenar la } \\
\text { comparecencia de un menor } \\
\text { de edad con discernimiento } \\
\text { a la audiencia repruebas } \\
\text { o una especial. }\end{array}$ & $\begin{array}{l}\text { Art. 194. Pruebas de oficio } \\
\text { Cuando los medios pro- } \\
\text { batorios ofrecidos por las } \\
\text { partes sean insuficientes para } \\
\text { formar convicción, el juez, } \\
\text { en decisión motivada e inim- } \\
\text { pugnable, puede ordenar } \\
\text { la actuación de los medios } \\
\text { probatorios adicionales que } \\
\text { considere convenientes. } \\
\text { Excepcionalmente el juez } \\
\text { puede ordenar la compa- } \\
\text { recencia de un menor de } \\
\text { edad con discernimiento } \\
\text { a la audiencia reprue- } \\
\text { bas o una especial. } \\
\text { Cuando la prueba se } \\
\text { actúe en segunda instan- } \\
\text { cia, deberá garantizarse } \\
\text { el contradictorio. }\end{array}$ & $\begin{array}{l}\text { Art. 194. Pruebas de oficio } \\
\text { Excepcionalmente, cuando los } \\
\text { medios probatorios ofrecidos } \\
\text { por las partes sean insuficientes } \\
\text { para formar convicción, el juez } \\
\text { de Primera o de Segunda Ins- } \\
\text { tancia, ordenará la actuación } \\
\text { de los medios probatorios adi- } \\
\text { cionales y pertinentes que con- } \\
\text { sidere necesarios para formar } \\
\text { convicción y resolver la contro- } \\
\text { versia, siempre que la fuente de } \\
\text { prueba haya sido citada por las } \\
\text { partes en el proceso. Con esta } \\
\text { actuación probatoria el Juez } \\
\text { cuidará de no reemplazar a las } \\
\text { partes en su carga probatoria, } \\
\text { y deberá asegurarles el derecho } \\
\text { de contradicción de la prueba. } \\
\text { La resolución que ordena las } \\
\text { pruebas de oficio debe estar } \\
\text { debidamente motivada, bajo } \\
\text { sanción de nulidad, siendo esta } \\
\text { resolución inimpugnable, siem- } \\
\text { pre que se ajuste a los límites } \\
\text { establecidos en este artículo. } \\
\text { En ninguna instancia o gra- } \\
\text { do se declarará la nulidad } \\
\text { de la sentencia por no ha- } \\
\text { berse ordenado la actuación } \\
\text { de las pruebas de oficio. } \\
\text { El juez puede ordenar de mane- } \\
\text { ra excepcional la comparecen- } \\
\text { cia de un menor de edad con } \\
\text { discernimiento a la audiencia } \\
\text { de pruebas o a una especial. }\end{array}$ \\
\hline
\end{tabular}

Fuente: Alfaro (2017). 


\subsection{Respecto de la imparcialidad del juez}

¿Se viola la imparcialidad del juez?, muchas veces las controversias múltiples existentes se originan a raíz de algunas imprecisiones conceptuales. Ahora debemos distinguir entre la impartialidad y la imparcialidad en sentido estricto. La referida imparcialidad es pues la imparcialidad objetiva, el juez es un tercero ajeno al proceso, él no puede ser parte, cumple funciones distintas de estas, mientras que la imparcialidad en sentido estricto hace referencia una imparcialidad subjetiva, el juez presenta ausencia de interés en el resultado del proceso, este requisito anímico es totalmente subjetivo, que va de la mano con la independencia judicial, siendo un presupuesto esencial para la imparcialidad del juez. Varios mencionan que si el juez aporta nuevas pruebas va a beneficiar a una de las partes directamente, pues no, al que beneficia es al proceso y a la labor judicial; debe quedar claro que el juez no sabe el resultado de la prueba que aportará, él no es mago, es difícil anticiparse a inferencias probatorias, no se sabe lo que va a ocurrir.

La iniciativa probatoria del juez no debe ser vista como un mal endémico, al contrario es un mecanismo que asegura la finalidad del proceso, a través de un juez investigador y no uno del montón, muchos en su afán de la celeridad del proceso no salvaguardan el lazo de prueba, verdad y proceso.

El juez no trae nuevos hechos al proceso, pues se delimita en la fuente de la prueba para ir en busca de la verdad relativa; su poder deber se activa, principalmente, ese deber, deber que tiene en el proceso y con las partes, así como con su vocación.

Antes de pasar al siguiente punto, es preciso que planteemos la posibilidad que las pruebas nuevas sean, pues, producto de la deducción de otros hechos, y constantemente suele suceder, es válido que el juez realice ello, siempre y cuando esta deducción provenga de hechos que están vinculados, es decir, ceñidos a la fuente de prueba, hay elementos de los cuales se infiere que sí hay derecho de actuar, más si la verdad es un valor esencial.

\subsection{Igualdad de las partes}

$\mathrm{Al}$ contrario, la prueba de oficio garantiza la igualdad de partes y no la vulnera, compartimos absolutamente la posición de Parra (2017, p. 98), quien señala que «la igualdad de las partes procesales al momento de acce- 
der a la justicia, específicamente frente a la etapa probatoria, es otro tema objeto de debate». En la práctica, se puede observar cómo una de las partes posee mayor conocimiento del derecho o tiene un apoderado con mayor experiencia en el ámbito del litigio, mientras que la otra parte puede tener un menor conocimiento legal y menores recursos para conseguir un profesional en derecho experimentado. De esta forma, el juez al decretar las pruebas de oficio, logra que las desigualdades que se presentan en el proceso se mitiguen.

Como resultado, el triunfo no será de aquella parte procesal que tiene mejores medios, sino de la justicia y la verdad, principales objetivos del proceso judicial. A lo largo del desarrollo de este artículo nos damos cuenta de que en la práctica los problemas son mayores, en la teoría es posible que resulta un poco más fácil, pero al aplicarla las necesidades saltan a la vista, tal como las barreras ya anteriormente mencionadas.

\subsection{Carga probatoria}

Los medios probatorios de oficio no implican que el juez sustituya a las partes en la obligación de demostrar la veracidad de sus afirmaciones. Según Picó I Junoy (1998, p. 17) «de lo que se trata es de la necesaria colaboración entre las partes y el juez para lograr el convencimiento acerca de la controversia». Lamentablemente, la cultura de justicia no está muy difundida en el Perú, es más, entre los jueces existe ese término vagamente, a pesar de que son los encargados del Estado para su administración.

En su mayoría, los jueces de primera instancia (civiles, mixtos o de paz letrado), cegados por el Código de Procedimientos Civiles y con muy poco interés por darle una ojeada al Código Procesal Civil, o lo que es aún peor, con tal de reducir su carga procesal, se han negado a aplicar la facultad del artículo 194 del Código Procesal Civil, por ello, a partir de esto concluimos que prefieren aplicar injusticia antes que hacer honor a la investidura del cargo que se les otorgó. Por otro lado, los jueces hasta hace algún tiempo utilizaban un camino fácil: declarar infundada una demanda cuando los medios probatorios eran insuficientes, es decir, este camino sonaba a algo que Alexander Rioja (2009) afirmaba: «[N]o sé lo que es lo que ha pasado porque la prueba es insuficiente, así que vamos a dejar el caso inconcluso». ¿Acaso esta era una respuesta digna de un magistrado representante de uno de los poderes del Estado? Afortunadamente, las salas superiores han veni- 
do revocando estas sentencias, ordenando a los jueces de primera instancia actuar con medios probatorios. Tal vez más de uno se avergonzó de su actuación. Así, a raíz de estos hechos realmente vergonzosos, relacionados con casos de mala aplicación del artículo 200 del Código Procesal Civil, es pertinente considerar en la actualidad las pruebas de oficio, estas no deben dejarse de lado.

La prueba de oficio no debe ser una piedra en el zapato de los jueces y/o doctrinarios, no debe un tema que cause discusión o debates interminables; la prueba de oficio es necesaria en todo proceso en el que exista incertidumbre en el juez para resolver un conflicto. La prueba de oficio es una herramienta que ayuda a todo operador de la justicia a tomar una decisión justa, una decisión que sea honorable de un representante del Estado porque ese es su deber, no reemplaza en ningún momento a las partes. Si, por ejemplo, se presenta la falta de cooperación de las partes, el juez tampoco está en la obligación de buscar las pruebas porque a una de las partes no tuvo la voluntad de reunir sus pruebas, ese es otro tema. La propuesta planteada trata de evidenciar que si la persona sí tuvo la intención e interés de juntar pruebas, aunque insuficientes, pero demostró que va a cooperar, el panorama es distinto, el juez aquí sí puede ejercer su poder discrecional.

\section{PROBLEMAS ENCONTRADOS EN EL PROYECTO DE RE- FORMA DEL CÓDIGO PROCESAL CIVIL}

Para seguir en el análisis de los problemas del Proyecto de Reforma del Código Procesal Civil, hemos optado por subrayar y colocar en cursiva las diferencias, mientras que las semejanzas se encuentran subrayadas con líneas entrecortadas.

En el Código Procesal Civil se señala que:

Excepcionalmente, cuando los medios probatorios ofrecidos por las partes sean insuficientes para formar convicción el Juez de Primera o de Segunda Instancia, ordenará la actuación de los medios probatorios adicionales y pertinentes que considere necesarios para formar convicción y resolver la controversia, siempre que la fuente de prueba haya sido citada por las partes en el proceso. Con esta actuación probatoria el Juez cuidará de no reemplazar a las partes en su carga probatoria, y deberá asegurarles el derecho de contradicción de la prueba. La resolución que ordena las pruebas de oficio debe estar debidamente motivada, bajo sanción de nulidad, siendo esta resolución inimpugnable, siempre que se ajuste a los límites establecidos en este artículo. 
En ninguna instancia o grado se declarará la nulidad de la sentencia por no haberse ordenado la actuación de las pruebas de oficio. El Juez puede ordenar de manera excepcional la comparecencia de un menor de edad con discernimiento a la audiencia de pruebas o a una especial.

Por su parte, en el Proyecto de Reforma:

Excepcionalmente, cuando los medios probatorios ofrecidos por las partes no sean suficientes para probar los hechos controvertidos, el juez de primera o de segunda instancia puede incorporar medios probatorios de oficio siempre que la existencia de los mismos haya sido invocada en alguna fuente de prueba citada en el proceso. Para tales efectos, el juez debe informar previamente a las partes la necesidad de incorporar un medio probatorio sobre algún hecho que a su juicio no estaría probado, debiendo las partes absolver lo indicado por el juez en un plazo de seis días, pudiendo ofrecer el medio probatorio necesario. Con la absolución o sin ella, el juez decide la incorporación de oficio o no del medio de prueba. En caso la decisión sea la de incorporar el medio probatorio, el juez otorga a las partes un plazo adicional de seis días para que puedan ejercer su derecho de defensa respecto de él, pudiendo ofrecer nuevos medios probatorios si fuera el caso. En ninguna instancia o grado se declara la nulidad de la sentencia por no haberse ordenado la incorporación de oficio de medios probatorios.»

Ya se habló del carácter excepcional de la prueba de oficio, además determinamos que es un poder discrecional. Sin embargo — para nosotrosaún existe un gran inconveniente: ¿Qué tan excepcional es realmente? Pues no creemos que tenga este carácter, porque existen etapas previas en las que se deben evaluar las pruebas que servirán al caso, y si no ello se realiza en el acto correspondiente y se espera hasta antes de decidir, implica unamayor pérdida de tiempo, ¿no creen que ya no es excepcional? Por otro lado respecto de que el juez debe informar previamente a las partes la necesidad de incorporar un medio probatorio sobre algún hecho que a su juicio no estaría probado, debiendo las partes absolver lo indicado por el juez en un plazo de seis días, pudiendo ofrecer el medio probatorio necesario; claro está que es necesaria la comunicación previa para la actuación de la iniciativa probatoria del juez; sin embargo, proponen que las partes ofrezcan medios probatorios. ¿Esto no se configuraría en una prueba extemporánea, de ser el caso, amerita o no que esté regulado en el artículo 194? Entonces, ¿La prueba de oficio no es exclusividad del juez? ¿Quién es el verdadero protagonista de la prueba de oficio? ¿El juez o las partes?

Nuestra respuesta, y probablemente la de la persona que está leyendo este material, sabe que la principal característica de la prueba de oficio es que 
como bien dice su nombre, está impulsada por el juez, esto no es advertido por el Proyecto de Reforma del Código Procesal Civil ya que al dar esta facultad a las partes, pierde la esencia misma de la iniciativa probatoria del juez, ya que ese protagonismo se le estaría dando a las partes, en tanto ya constituye una prueba extemporánea porque son los sujetos procesales los que ingresan ese nuevo medio probatorio y no es juez. Bajo estas mismas líneas, nos preguntamos: ¿Por qué no optar por un juez responsable y garante? ¿Cuántas oportunidades más se pretende otorgar a las partes para que presenten pruebas?

Finalmente, «en caso la decisión sea la de incorporar el medio probatorio, el juez otorga a las partes un plazo adicional de seis días para que puedan ejercer su derecho de defensa respecto de él, pudiendo ofrecer nuevos medios probatorios si fuera el caso». Es pertinente que se le otorgue a la otra parte un plazo para que pueda ejercer su derecho a la defensa, y también pueda ofrecer más pruebas, y es que 6 días resultan insuficientes, estamos equiparando ello para todos los procesos como el de conocimiento, el abreviado y otros, sin tomar en cuenta la complejidad del proceso, la actitud del demandado y demandante. Asimismo, no se está considerando qué tipo de proceso sería el adecuado para trabajar con este plazo.

Si bien es cierto debemos observar cómo es que en el plano práctico se desarrollaría esta institución, ya que, según nuestra opinión - como es bien sabido-, los operadores del derecho pueden aprovechar esta situación para dilatar el proceso, situación que debe evitarse en un proceso, amparándonos, en esta parte, en los principios de economía procesal y preclusión.

\section{HABLEMOS DE LAS PROPUESTAS Y SUS REQUISITOS}

Según lo expuesto, sugerimos considerar los siguientes criterios:

1. El juez, en la fijación de puntos controvertidos y en la admisión de los medios de prueba, debe evaluar las pruebas que serán necesarias para la decisión; de advertir la falta de ellas, comunicará a las partes la necesidad de introducirlas. Si a pesar de ello, no lo han hecho, el juez debe dejar constancia de ello; así mismo se considera como prueba de oficio aquella que luego de la fijación y admisión no pudo ser advertida. 
2. Se comunicará mediante una audiencia que el juez ejercerá su iniciativa probatoria, motivando sus razones.

3. En dicha audiencia las partes serán las que definan el plazo, obviamente razonable, para que el juez aporte las pruebas que considere relevantes; si las partes acuerdan aportar medios probatorios y en aras de salvaguardar la esencia de la prueba de oficio, el juez hará suyas las pruebas y las incorporará al proceso.

4. Si bien es cierto, la prueba de oficio es un poder discrecional, en tanto debe generar seguridad jurídica, a lo que denominaremos prueba de oficio vinculante.

\section{1. ¿Por qué estos requisitos son necesarios?}

\subsubsection{Criterio 1}

Respecto del Criterio 1, compartimos la idea de Renzo Cavani (2016, p. 81) cuando refiere que

[...] la práctica debe ir más allá de la delimitación de los puntos en controversia, para pasar a desempeñar una compleja actividad de organización del proceso, que comprende, a su vez, tres subactividades consistentes en: i) la delimitación del objeto litigioso; ii) la admisibilidad de los medios probatorios (siempre que no sea una cuestión de puro derecho) y iii) la determinación de los argumentos fáctico-jurídicos. Esta propuesta se justifica, además, en que contribuye con una mayor promoción de los derechos fundamentales al contradictorio, a la prueba y a la motivación de las decisiones judiciales [...].

Con base a lo citado, es prudente referirnos al rol del nuevo juez civil, hablar de un juez garante y responsable de inspeccionar que las actuaciones que surtan dentro del proceso se realicen siguiendo los parámetros legales, planteamos un juez educado para investigar; creemos que es importante que en la fijación de puntos controvertidos y en la admisión de pruebas se evalúe correctamente la pertinencia y utilidad de las pruebas, no que se haga una mera transcripción de pretensiones, que sea el juez quien verifique realmente un punto controvertido, no uno en el que las partes estén de acuerdo, es necesario que ante cada hecho controvertido se advierta cuál es la prueba pertinente y útil que ayudará a dicho esclarecimiento.

Si hubieran pruebas por hechos controvertidos y el juez fuera más diligente, ya no tendríamos que esperar actuar una prueba de oficio antes de decidir, y de ser el caso que a pesar de la advertencia que se realizó no se 
presentó esa prueba o que nunca se pudo advertir ello, realmente la prueba de oficio será excepcional, de manera que no perderá el ánimo heurístico epistemológico, ya que la idea es la organización del proceso (de la causa).

Cuando nos referimos a que las partes deben presentar mínimamente una prueba, se advierte, al menos, que han tenido ese interés de probar, para así evitar la discusión de que estarían renunciando a la carga procesal, que obviamente le corresponde a las partes y no al juez, esto tiene una conexión con el principio de cooperación procesal, ciertamente Jorge W. Peyrano, Cavani (2016, p. 181) fija que en todos los supuestos su funcionamiento revela que el proceso es como una empresa común cuyo feliz resultado exige la colaboración de ambas partes, éstas deben tratar de obtener todas las pruebas posibles para que puedan nutrir al juez, pero puede suceder que encuentren pruebas pero lastimosamente insuficientes, caso contrario es cuando hay falta de cooperación por las partes, a ellos les viene en ganar nutrir al juez, entonces aquí el juez no tiene por qué actuar pruebas de oficio. Fijémonos que no queremos ser partícipes de gasto, tiempo y esfuerzo innecesario, siendo necesaria que la parte presente al menos una prueba pero no tan alejada de la realidad ni de la relevancia.

\subsubsection{Criterio 2}

Es importante poner de conocimiento, a través de las audiencias, que el juez ejercitará su iniciativa probatoria, donde deberá motivar las razones del por qué considera que las pruebas son insuficientes.

La resolución en la cual mencionará que se aplicará prueba de oficio debe estar motivada; así mismo el juez debe explicar sus razones por las cuales considera este poder discrecional; esta resolución es motivada e inimpugnable, muchos difieren de ello, pero repetimos que en teoría suele ser más sencillo que en la práctica. Si la resolución fuera impugnable, el proceso se alargaría innecesariamente, porque la insuficiencia debe ser curada, ya una vez que ingresó el nuevo medio de prueba y el juez decida, obviamente se puede impugnar ya que es un derecho de por sí; no seamos tan tercos en decir «y su derecho...», seamos agentes de cambio, aceptemos la cultura investigativa del juez, él lo presenció y quiere superarlo a través de la prueba de oficio; nada nos impide de impugnar después de la decisión, en la casuística se hará más fácil. 


\subsubsection{Criterio 3}

Al darle la facultad a las partes de que sean ellas las que determinen el plazo para que el juez presente los medios probatorios adicionales, estamos evitando que el juez pueda caer en parcialidad. Denotemos en un contexto, si hablamos de que el juez aplicará este poder discrecional en aras de alcanzar el fin del proceso, lo cual es totalmente válido — como ya lo justificamospodría ser que una de las partes sienta algún tipo de vulneración, por ello se les encarga a estas determinar el plazo para las nuevas aportaciones, que evidentemente sea razonable, estimamos conveniente que el plazo mínimo sea de 10 días y el máximo de 15 días de acuerdo al caso en concreto.

Los medios probatorios adicionales que el juez considere convenientes, deben derivar de la fuente de la prueba citada por las partes. Ahora, podría ser que las partes acuerden en aportar medios probatorios, pero si estas aportaran esas pruebas, ya no estaríamos hablando de pruebas de oficio sino de pruebas extemporáneas, es más, el plazo para la presentación de estas últimas es de cinco días, por tanto, tampoco tienen sentido, viendo ello consideramos que es necesario que el juez haga suyas estas pruebas, obviamente en aras de salvaguardar la esencia de la iniciativa probatoria del juez; de manera que se incluyan al proceso.

\subsubsection{Criterio 4}

Si bien es cierto, la prueba de oficio es un poder discrecional, en tanto debe generar seguridad jurídica, a lo que denominaremos prueba de oficio vinculante, dentro de los valores aléticos que el ordenamiento jurídico pretende implantar mediante la correcta administración de justicia se encuentra la seguridad jurídica, que es la consecuencia directa de resoluciones judiciales no contradictorias, puesto que donde hay la misma razón yace el mismo derecho, la prueba de oficio caería en un vacío en cuanto a su aplicación en aquellos casos donde que pese a solo presentarse un medio probatorio, pueda emitirse una solución justa, esto basado en los precedentes en sus diversas manifestaciones (autoprecedente, precedente horizontal, precedente vertical], no se pretende desvirtuar el poder que ostentan los jueces bajo el esquema de la socialización del proceso, sino moldearlo para su mayor efectividad, siguiendo de cerca el principio de economía procesal en su clara manifestación de la celeridad procesal, ¿es correcto que ante casos similares se emitan decisiones contrarias? Obviamente la respuesta es 
negativa; al aletargar la justicia esta va perdiendo su fulgor.

Como bien mencionaba, Lorenzetti (2006, p. 183), «el juez debe de ejecutar su discrecionalidad realizando tres acciones, primero: mirando hacia atrás y fijándose en los precedentes judiciales establecidos; segundo: mirando hacia arriba teniendo en cuenta la estructura del sistema jurídico y guardando el debido respeto a las normas eje y, por último, mirando hacia adelante para así prever aproximativamente las consecuencias de la decisión que se llegará a emitir».

Todo aparato jurisdiccional debe brindar los cauces para emitir una solución justa, y esta se logrará con la atinada actividad del juez como director del proceso y no como un mero árbitro futbolístico, que solo mira y atiende a los jugadores. Kelsen (2008), en su ensayo ¿Qué es justicia?, conceptualiza y menciona que «la justicia para mí, se da en aquel orden social bajo cuya protección puede progresar la búsqueda de la verdad». El juez debe propugnar encontrar la certeza más aproximada a las aseveraciones esgrimidas por las partes, máxime si este debe impulsar la seguridad jurídica con decisiones uniformes, respetando las afirmaciones presentadas, la fuente de prueba y sobre todo el derecho fundamental a la defensa, estos como criterios básicos e indispensables para una correcta administración de justicia.

Consideramos que la correcta aplicación de la prueba de oficio brindará criterios objetivos de uniformización para casos futuros similares, y con el baremo de aquella mirada atrás, arriba y hacia adelante que los jueces deben realizar propugnarán el alejamiento de la subjetividad en casos concretos, para dar paso a la evolución de este precepto jurídico, a éstos se le denominará prueba de oficio vinculante, ya que se aplicará a los casos concretos similares.

\section{CONCLUSIONES}

- La prueba de oficio como la fiel manifestación del despertar de los jueces juega un rol decisivo al momento de impartir justicia, teniendo como límites propios del sistema jurídico la mirada fiel a los principios inspiradores constitucionales, propugnando la interdicción de la arbitrariedad respectiva, ya no simplemente mirando la literalidad del texto normativo, sino siendo más agudos, mirando el alma del ordenamiento 
jurídico; teniendo clarificada la mirada en su finalidad constitutiva y la búsqueda de su mejor desenvolvimiento, ello en relación al lazo tridimensional entre prueba, proceso y verdad.

- La justicia, uno de los valores-principios más entrañables de toda sociedad desde sus tiempos más remotos, debe de ser propugnada seriamente desde los tribunales de justicia mediante los pasos de la heterocomposición, puesto que la contribución social que se expide en una resolución judicial no solo debe ser tomada por el juez como una solución inter partes, sino también bajo el interés de la sociedad en su conjunto, manteniendo así un valor común que se ha buscado por generaciones: la paz social en justicia.

- El Proyecto de Reforma del Código Procesal Civil, en su artículo III del título preliminar, plantea que la finalidad del proceso es brindar una adecuada, oportuna y eficaz protección a los derechos e intereses, subsumiéndose en el criterio de las políticas públicas; sin lugar a duda, este planteamiento es muy acertado porque al juez le tiene que importar que gane el proceso quien deba ganarlo de acuerdo con la regulación y los hechos, todo ello con base a la verdad probada.

- La prueba de oficio más que un poder es responsabilidad jurisdiccional para con los justiciables, en consecuencia es innegable la dinámica constante del sistema jurídico que debe ser maleable a los fenómenos sociales, estableciendo hitos en cuanto a decisiones ya esgrimidas con anterioridad para no recaer en decisiones contradictorias que fatalmente generan desconfianza en la ciudadanía y a la vez el desmedro de la justicia que imparte el órgano jurisdiccional, es por ello vital que este poder discrecional encuentre un parangón en los principios constitucionales y las limitaciones que el mismo texto normativo brinda, expurgando todo aspecto decisorio plasmado en una resolución judicial donde por obvias razones prima el subjetivismo en su máximo esplendor.

- Luego del análisis de algunos problemas del Proyecto de Reforma, como el peligro de la pérdida de la esencia de la prueba de oficio, sugerimos se tomen en cuenta los siguientes criterios: i) Las partes deben presentar mínimamente una prueba, ii) Se comunicará mediante una audiencia que el juez ejercerá su iniciativa probatoria, motivando sus razones, iii) En dicha audiencia las partes serán las que definan el plazo, obviamente razonable, para que el juez aporte las pruebas que conside- 
re relevantes, si las partes acuerdan en aportar medios probatorios y en aras de salvaguardar la esencia de la prueba de oficio, el juez hará suyas las pruebas y las incorporará al proceso, y iv) Si bien es cierto, la prueba de oficio es un poder discrecional, en tanto debe generar seguridad jurídica, a lo que denominaremos prueba de oficio vinculante.

- La predictibilidad es uno de los ejes rotundamente necesarios del ordenamiento jurídico, obligación que le toca efectuar a los jueces activamente bajo el riesgo inminente de devenir lo mencionado anteriormente en inaplicable a la realidad. «Donde hay la misma razón hay el mismo derecho» y, por ende, este poder del juez devendría en terciario o en principal en cuanto a su aplicación, en aquel caso que evidencia aquel aforismo. Un juez elogiable no mira solo sus narices al tomar una decisión, ni mucho menos lo hace en base a su estado anímico, sino mediante una mirada tridimensional.

Así pues, todos los aportes y criterios planteados nos permitirán simplificar los casos en los cuales se debe aplicar la iniciativa probatoria, evitando el incremento de la carga procesal para dinamizar el proceso. Creemos que nuestras propuestas van a ser muy útiles a la legislación procesal civil peruana y por qué no a las demás legislaciones extranjeras, al lector gracias por acompañarnos en esta aventura investigativa.

\section{BIBLIOGRAFÍA}

Alfaro, L. (2017). La iniciativa probatoria del juez. Lima: Grijley.

Arazi, R. (1995). Derecho procesal civily comercial. Buenos Aires: Rubinzal-Culzoni.

Cavani, R. (2016). Fijación de puntos controvertidos: una guía para jueces y árbitros. Revista de la Maestría en Derecho Procesal, volumen 6(2). Recuperado de http://revistas.pucp.edu.pe/derechoprocesal

Devis, H. (1985). Teoría del proceso. Volumen II. Buenos Aires: Editorial Universidad. Ferrer, J. (2005). Prueba y verdad en el Derecho. 2. ${ }^{a}$ ed. Madrid: Marcial Pons.

Gaitán, L. (2010). La prueba de oficio en el proceso civil: ¿Imparcialidad del juez e igualdad de las partes? Revista de Derecho Privado. 23; Bogotá; 2010. Recuperado de http://www.redalyc.org/çpdf/3600/360033192005.pdf

Kelsen, H. (2008). ¿Qué es justicia? Barcelona: Arial.

Ledesma, M. (2017). Análisis de las pruebas de oficio. Lima: Gaceta Jurídica. 
Lorenzetti, R. (2006). Teoría de la decisión judicial. Fundamento de Derecho. Santa Fe: Rubinzal-Culzoni.

Parra, J. (2007). Manual de derecho probatorio. 16. ${ }^{a}$ ed. Bogotá: Librería Ediciones del Profesional.

Picó I Junoy, J. (1998). La iniciativa probatoria del juez civil y sus límites. Revista Peruana de Derecho Procesal, volumen II. Lima: Communitas.

Real Academia Española. Diccionario de la lengua española. 23. ${ }^{\mathrm{a}}$ ed. Disponible en http://www.rae.es/

Rioja, A. (2009). El artículo $194^{\circ}$ del Código Procesal Civil: una valiosa herramienta para la administración de justicia. Recuperado de http://blog.pucp.edu.pe/ blog/seminariotallerdpc/2009/11/23/el-articulo-194-del-codigo-procesal-civil-una-valiosa-herramienta-para-la-administracion-de-justicia/

Taruffo, M. (2013). Verdad, prueba y motivación en la decisión sobre los hechos. Serie Cuadernos de Divulgación de la Justicia Electoral 20. México: Tribunal Electoral del Poder Judicial de la Federación.

Taruffo, M. (2009). Poderes probatorios de las partes y del juez en Europa. Lima: Ara Editores. 